\title{
Energy production and C02emisson efficiency of eight European countries in the manufacturing area
}

Kelly P. Murillo ${ }^{1}$, Eugénio M. Rocha ${ }^{1}$ and Clara Inés PardoMartínez ${ }^{2,3}$.

${ }^{1}$ Center for Research and Development in Mathematics and Applications (CIDMA)

Department of Mathematics, University of Aveiro, 3810--193 Aveiro, Portugal

${ }^{2}$ School of Administration, Universidad del Rosario, Bogotá, Colombia

${ }^{3}$ Observatory of Science and Technology (OCyT), Bogotá, Colombia

kellymurillo@ua.pt

eugenio@ua.pt

clara.pardo@urosario.edu.co; cipmusa@yahoo.com

\begin{abstract}
Anenergy efficiency comparison of manufacturing sectors of eight European countries, between 2008-2013, is performed in order to understand how the world economical crisis affected theirperformance. The analysis rely in a combination of multidirectional efficiency analysis blended with other techniques, as nc-value, principal component analysismixed with a dimensionality test.The purpose is to analyse three different approaches organized by: (a) a general viewpoint on countries/sectors; (b) sectors and inefficiency input usage; and (c) intensive versus non-intensive energy sectors. We also consider non-normalized and normalized data, by the total number of firms. The results indicate that the great majority of sectors/countries analyzed show a decrease in the $\mathrm{CO} 2$ emissions. Since thecalculated inefficiency indexes expose the sectors which used inputs in excess, we found that the most efficient sectors were: basic metals; rubber and plastic products, products of wood and cork; textiles, wearing apparel and of leather products; whereas chemical products and food;beverages and tobacco products were the most inefficient sectors. Our approach also give indicators about the way each sector/country was affected by the crisis and how they were able to react or adapt to it.
\end{abstract}

Indexing terms/Keywords:Energy efficiency and inefficiency, manufacturing industry sectors, world economical crisis, $\mathrm{C} 02$ emissions.

Mathematics Subject Classification (2010): 90C05; 62-07;62P20.

Type (Method/Approach):Multidirectional Efficiency Analysis, PCA, NC-Value, Clustering Analysis

Supporting Agencies :

Language : English

Date of Submission : 2018-05-18

Date of Acceptance : 2018-06-20

Date of Publication : 2018-07-12

ISSN : 2278-5612

Volume : 13 Issue : 1

Journal : INTENATIONAL JOURNAL OF MANAGEMENT AND INFORMATION TECHNOLOGY

Publisher : CIRWORLD

Website : https://cirworld.com

This work is licensed under a Creative Commons Attribution 4.0 International License. 


\section{Introduction}

Energy efficiency plays an important role in the progress of any country, an intelligent use of energy is a key factor to improve productivity in the industrial area and therefore in the economy growth. On the opposite side of the spectrum, energy inefficiency tends to directly/indirectly penalize the environment and the country resources. The benefits of higher energy efficiency are numerous, it includes improvements resource management, disposable income, health and well being with the reduction of greenhouse gas emissions and local air pollution, among others. Hence, we may say that energy efficiency is of fundamental importance to society.

It is well known that nearly a third of global energy demand and $\mathrm{CO} 2$ emissions are attributable to manufacturing, especially to big primary materials industries such as chemicals and petrochemicals, iron and steel, cement, paper and aluminium. In this work, it is compared the energy efficiency of manufacturing industries concentrated in the following eight sectors: FOOD, TEXT, WOOD, PAPER, CHEM, RUB, MET and EQUIP, described in detail in Section 2.1. The eight countries under study are Denmark (DK), Finland (FI), Germany (DE), Hungary (HU), Republic of Ireland (IE), Portugal (PT), Sweden (SE) and United Kingdom (UK), i.e. Scotland, England, Wales and Northern Ireland. Although it is possible to establish some similarities between the countries studied, they have social, political and economic aspects that make them very different with each other and which can lead to interesting results on the energy efficiency in the sectors considered. This is the main reason why we have selected a diverse group of countries that is strong within its specific characteristics but has different abilities to meet the energy needs of its industrial sector. In fact, in 2011, five of these countries were included by the Japanese Bank Nomura within the list of the most efficient countries in the world: $\operatorname{IE}(3), \mathrm{DK}(4), \mathrm{UK}(5) ; \mathrm{DE}(10)$ and $\mathrm{SE}(11)$. The number in the bracket state the rank in the list. The differences in these eight European countries become more evident when their corresponding classifications are reviewed in global economies lists, e.g. according to the International Monetary Fund (2015): DE(4), UK(5), SE(23), DK(36), IE(43), FI(44), PT(46) and HU(58); and according to the World Bank (2014): DE(4), UK(5), SE(21), DK(34), Fl(40), IE(42), PT(45) and HU(58). We choose the period 2008-2013 due to our special interest in the European crisis (since the end of 2008), because such implies several notable consequences such as less production in most sectors, a macroeconomic imbalance in all Europe, and some industry reaction strategies by compensation measures. We did not extend the study to years above 2013 due to the lack of complete and reliable information for the ten variables needed for all the eight countries and eight sectors. Further characterization of the data can be found in Section 2.1.

We find in the literature several (mathematical) models to measure energy efficiency with different key objectives. Models that appeared in [1,2] can be used to measure energy efficiency when the underlying objective is the conservation of energy and maintenance of environmental quality by reducing energy use and maintaining the level of output. In [3], theirthird modelis used for achieving energy efficiency when it is based on the minimising costs during periods of relatively high energy prices. In [4], it is presented two different models to measureenergy efficiency of Gulf Cooperation Council countries(Saudi Arabia, Bahrain, Kuwait, Qatar, Oman and United Arab Emirates). The first model emphasizes more energy intensity, and the second model incorporates other economic factors inthe measurement. In [5], techniques as Data Envelopment Analysis (DEA),

Slack-based Measure (SBM) and Variant Analysis Window (VAW) were used to measure and analyze the total-factor energy efficiency index in the BRICS countries(Brazil, Russia, India, China and South Africa). In [6], energy comsumption patterns for rose production in Iran was investigated and DEA was applied to analyze the technical and scale efficiencies of farmers with respect to energy use in crop production. In contrast to the standard DEA, proposed by [1],in the Multidirectional Efficiency Analysis (MEA), proposed by [7]and further developed in [32, 33]; the input reduction andoutput expansion are selected proportionally to the potentialimprovements in efficiency identified by considering the improvementpotential separately in each input variable and output variable. In [8], MEA is used to evaluate the environmental efficiency of industrial sectors of Chinese major cities. In [9], a nonradial DEA model with MEA involving undesirable outputs for the measurement of regional energy and environmental efficiency of China's transportation sector during the period 2006--2010. Many other relevant papers use MEA instead of the traditional DEA, e.g. see [10, 11, 12, 13].

The main contributions of this work are as follows: (a) we estimate the relative efficiency of manufacturing sectors at different aggregation levels, e.g. by country/sector or by (dynamically obtained) intensive vs nonintensive sectors, taking into account multiple inputs and outputs; (b) results may allow to identify potential improvements in efficiency according to relationship between inputs and outputs; and (c) we provided information about the behaviour of efficient groups versus non-efficient groups, which are important to develop new and adequate energy policies according to specific requirements specific, namely to decrease $\mathrm{CO} 2$ 
emissions. At the end, we provide a global and rough comparison of the countries efficiency performances by using a weighted rank index.

The paper is organized in three parts. In the first part, we characterize the dataset and sources, the methodology and the mathematical techniques used (see Section 2), then we present the results (see Section 3 ), and finish with some conclusions and remarks (see Section 4). In detail, to analyze the energy efficiency, of the eight countries in the eight industrial sectors during 2008-2013, we process the data into three different approaches, see Figure 1 and Figure 2.

The discussion of the approaches will be presented in Section 3 as: $\left(A_{1}\right)$ a general view by country/sectors;

$\left(A_{2}\right)$ analysis of sectors and inefficiency input usage; and $\left(A_{2}\right)$ analysis of intensive and non-intensive energy

sectors. In all approaches, we perform a relative ranking to determine, characterize, and compare which are the most efficient sectors and countries, using a nonparametric deterministic method based on MEA (see Section 2.3.1. We will reapply the MEA model to sectors with maximal efficiency, this time taking into account only the most significant input and output variables, such will allow to differentiate elements on the efficiency boundary. The selection of most significant variables were found by using the well known Principal Component Analysis (PCA), proposed in [14], togetherwith a dimensionality test described in [15] (see Section 2.3.3), in order to avoid loss of information or the introduction of random noise. Further, we determine which are the intensive and non-intensive sectors, using Cluster Analysis (CA), in contrast to the traditional way of classification by a static rule. We found that the best (mathematical) aggregation is made using an algorithm for non-hierarchical grouping, the Partitioning Around Medoids (PAM) proposed in [16] and based on the GDM2 distance measure proposed in [17] (see Section 2.3.2). We also compare the statistics of efficient groups with those of non-efficient groups, using a technique developed in [18], which is based on a distribution intersection coefficient (so-called NC-value), see Section 2.3.5.

The remaining sections are organized as follows. Section 2 provides the data and methodology used in this study. Section 3 presents the main results. Section 4 summarizes the main conclusions of this study and some discussion.

For processing the data and obtain the results presented here, we develop a general SDL package based on the $\mathrm{R}$ language that is available online on http://sdl-vm2.mathdir.org/docs/packages/rDATA/1.3/package.html.

Note that, due to size constraints, not all the tables and figures obtained regarding the three approaches and several algorithm applied are embedded in the document. However, all of them are available online. The reader interested in further data, tables and graphs can check the web address http://sdlvm2.mathdir.org/docs/prjs/000012-public.html and the reader may check the references indicated throughout the document to access them.In particular, we globally use the notation @[xxx] to denote the url http://tinyurl.com/xxx, so Table A.2.1@[h4s63qj] means the Table A.2.1 found at http://tinyurl.com/h4s63qj.

\section{Data, Methodology and Techniques}

\subsection{Characterization of the (normalized) data}

Denote by $S_{v} C_{v} T$ the sets of sectors, countries, and years under study. The initial dataset considers data, for

the set $T$ of years from 2008 to 2013, collected from Eurostata and Odyssee databases, which comprises

financial and energy information of European countries operating in the manufacturing, besides other information. The study is focused in the following set $C$ of eight countries: Denmark (DK), Finland (FI),

Germany (DE), Hungary (HU), Republic of Ireland (IE), Portugal (PT), Sweden (SE) and United Kingdom (UK); and the set Imathcal\{S\} of eight sectors, where the corresponding NACE Rev.2 statisticalclassification of economic activities in the European Country, section C, codes between 10 and 33 in parentheses: FOOD (C10-C12); TEXT (C13-C15); WOOD (C16); PAPER (C17); CHEM (C20); RUB (C22); MET (C24) and EQUIP (C28).

From the initial data, we extracted ten variables described in Table 1. Note that PV is measured as the amount actually produced by the unit, based on sales, including changes in stocks; VA is defined at factor costs as the gross income from operating activities after adjusting for operating subsidies and indirect taxes; and INV represents the per-unit production of goods, which have not been consumed. 
Table 1:Variables definition.

\begin{tabular}{|l|l|l|}
\hline Variable & \multicolumn{1}{|c|}{ Definition } & \multicolumn{1}{|c|}{ Unity } \\
\hline CO2 & CO2 emissions & Tonnes \\
PV & Production value & Euros-2005 \\
VA & Value added & Euros-2005 \\
$\mathrm{E}$ & Energy & Mtoe \\
$\mathrm{K}$ & Capital & Million euro \\
LAB & Labour number & Number of employees \\
INV & Investments & Euros-2005 \\
Ele & Electricity & Mtoe \\
EP & Energy price & Million euro \\
FOFUEL & The sum of coal, oil, natural gas & Mtoe \\
\hline
\end{tabular}

Note that we will use (firm) normalized data for most of the analyzes. Such will be useful for comparison reasons, however the MEA score (up to computational round errors) will be the same, when compared with non-normalized data, since we multiple by the same value the inputs and outputs variables for each sector, country and year. See details in the next subsection. In concrete, the normalization means that the value in each variable is divided by the number of firms in each country in the corresponding sector (see Table A.2.1@[h4s63ai]].The basic statistics as sum, mean, standard deviation is available in the Tables A.6.1@[h4s63ai] to A.6.8@[h4s63ai]. In some situations, we will present the comparison between normalized data versus non-normalized data.

\subsection{Methodology}

As stated in the introduction, the data was processed by a SDL package that we implemented, which combines MEA with PCA, dimensional test, CA and NC-value (see details below). Because of the way the data was gathered, it is initially grouped by countries. To extract the most information from the given data, we consider the three approaches with the structure shown in Figure 1 and Figure 2.

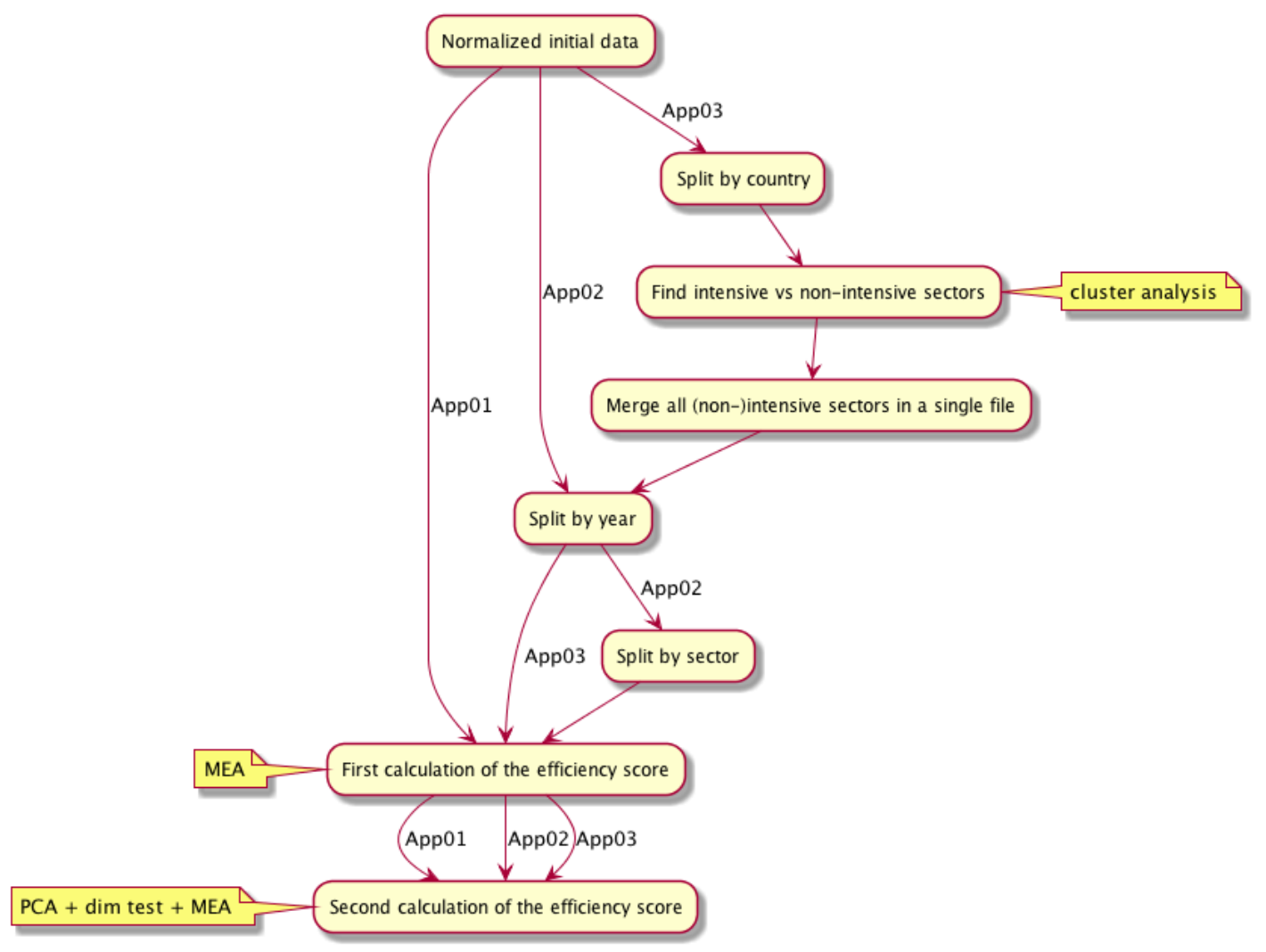

Figure 1: First part of the structure of the approaches considered for the normalized data. 
In order to distinguish efficient sectors in more detail, the MEA algorithm was again applied to the data containing only the full efficiency sectors for a reduced set of variables. The MEA algorithm was applied (for a first time) using as inputs: E, K, LAB, INV, ELE, FOFUEL and EP; and as outputs: CO2, PV and VA. We made a second application of the MEA algorithm with the five inputs: E, K, LAB, INV and EP; and the two outputs: $\mathrm{CO} 2$ and PV, where these reduced (relevant) set of variables where found by using the techniques of Section 2.3.3. Such technique allow us to redefine and improve the relative ranking obtained in the first application of MEA, in particular, distinguishing between some sectors that where in the set of full efficiency. Since all the approaches are interrelated, and share the same original data, when presenting the results we will show only the most relevant ones in each case and those that directly contribute to the main objective of this work. On this basis, the first part of the analysis will be mainly through the MEA efficiency score. The second one, through the results of the inefficiency index; and the last one, through the results of cluster, analysis efficiency ratios and the NC-values.

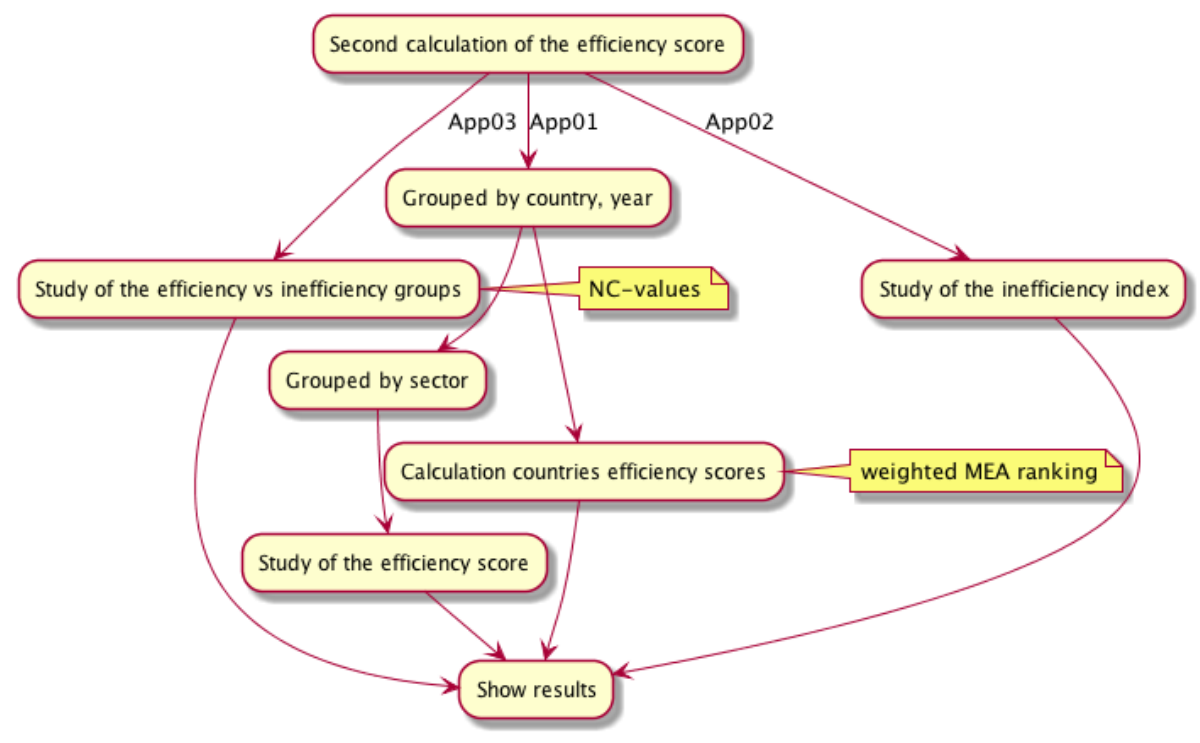

Figure 2:Second part of the structure of the approaches considered for the normalized data, a continuation of the first part.

\subsection{Mathematical techniques}

Let $n=(s, c, t) \in N$ be a ternary identifying the sector $s \in S$, country $c \in C$ and year $t \in T$, which we call a sector/country/year ternary, and $[m]$ denotes the set $\{1, \ldots, m\}$, for some $m \in N$.

We consider that any given ternary $n \in N$ produces $l$ outputs $y_{j}(n), j \in[]$, using $I$ inputs $x_{i}(n), i \in[I]$, where the first $1<D \leq I$ inputs are the so-called discretionary inputs, i.e. variables that enter into the optimization

process, because the non-discretionary inputs are variables that cannot be changed. Hence, $x(n) \in \mathrm{R}^{\prime}$ is the vector of all the inputs and $y(n) \in \mathrm{R}^{\mathrm{J}}$ is the vector of all the outputs, for a given sector/country/year ternary $n \in N$. Our dataset $Z=\{Z(n)\}_{n \in \mathrm{N}}$ is the set of values $Z(n)=(x(n), y(n))$ for all $n \in$ N.We will denote the non-

normalized initial data set by $\bar{z}_{0}$ and the normalized initial dataset by $Z_{0}$.

\subsubsection{Multidirectional efficiency analysis}

The Multidirectional Efficiency Analysis (MEA) is used in this work for the analyze of theenergy efficiency development in the manufacturing sector, considering as inputs: E, K, LAB, INV, ELE, FOFUEL and EP; and as outputs: $\mathrm{CO} 2, \mathrm{PV}$ and VA. Note that for some output variables (e.g. CO2) a higher production is bad, so in such situations and to be compatible with the MEA criteria, in the calculations we always consider the socalled variable complement, which is defined as the maximum value of the output variable in all the database minus the value of the variable for the unit under consideration. 
Energy efficiency somehow means in a general sense "using less energy to provide the same service", so we may translate it mathematically as minimizing the consumption of energy, electricity, coal, oil and natural gas, to improve the efficiency level; therefore the model used in this study is the input-oriented model, which minimizes inputs while satisfying at least the given output levels [19].

Since MEA is a relative ranking is quite important to clearly specify what we are comparing with. To be precise, the calculation of the efficiency score (i.e. for us the MEA score) is done as following: in App01, to a unique dataset $Z_{1}$ which coincides with $Z_{0}$ in App02, to 48 datasets $Z_{1}(s, t)$ indexed by the pair

\section{$(s, t) \in S x T$ extracted}

from $Z_{0}$; and in App03, to 12 datasets $Z_{2}(r, t)$ indexed by $(r, t) \in R x T$ extracted from $Z_{0}$ where $R=\{1,2\}$ is the set of intensive/non-intensive sectors clusters.

For a given dataset $Z=\{z(n)\}_{N}$ with $z(n)=(x(n), y(n))$, the MEA score of each $n \in N$ is then defined as

$$
\mathrm{MEA}_{z}(\mathrm{n})=\frac{\frac{1}{Y^{*}(\mathrm{n})}-\frac{1}{D} \sum_{i=1}^{D} \frac{x_{1}[\mathrm{n})-Q_{i}^{*}(\mathrm{n})}{x_{i}(\mathrm{n})}}{\frac{1}{\gamma^{*}(\mathrm{n})}+\frac{1}{J} \sum_{j=1}^{J} \frac{\beta_{j}^{*}(\mathrm{n})-y_{j}(\mathrm{n})^{y}}{y_{j}(\mathrm{n})}}
$$

where $\alpha_{i}^{*}(n), \beta_{j}{ }^{*}(\bar{n})$ and $\gamma^{*}(\bar{n})$ represent the corresponding optimal solutions to the linear optimization problems

$P_{i}^{\alpha}(z, n), P_{j}^{\beta}(z, n)$ and $P^{\gamma}(z, n, \alpha *, \beta *)$. Further details, interested readers can review the description of the model used in this work, available online on http://sdl-vm2.mathdir.org/docs/ downloads/Appendix.pdf

\subsubsection{Cluster analysis}

Cluster analysis is the set of techniques to group a set of objects in such a way that objects in the same group share similar properties, in general, the similarity is measured by some kind of distance. As expected there are several ways to do such task. In this work, the cluster analysis is performed to dynamically and more precisely determine which are the intensive and non-intensive sectors in each country. Recall that our data changes along years so some fixed criteria applied to one year may give a different classification when applied to another year. We need a more general perspective.

To overcome the variability of different methods that may be used, we use the R package clusterSim[20], which addresses the searching for an optimal clustering procedure for a given dataset. Because of the characteristics of our data, such corresponds to path number 3 in Table D.1.2@[znodlbp]. Our package applies these methods to files containing data grouped by country and year, such means that we study the cluster variation of the sectors in each country, along years. However, as presented in Table 3, the sectors are quite stable with regards to the optimal cluster separation found. Since these clustering methods are not multiplicative invariant, contrary to the MEA score, we show the differences between normalized and nonnormalized data in Section 3.2.

The best method found is the Partition Around Medoid (PAM), which is the most common realization of kmedoid clustering, i.e. the algorithm is related to the k-means algorithm and the medoid shift algorithm [21].The distance is the GDM2, i.e. the GDM distance proposed by Walesiak for ordinal data [17].Besides the expected cluster size of two, we also tested for cluster size of three, but the results always indicate that two clusters are the best choice. Three clusters would mean the existence of an intermediate intensive group, which do not happen.

\subsubsection{Principal component analysis with a test of dimensionality}

As described previously (see Figure 1), we apply the MEA algorithm twice in order two differentiate further the units that are classified as top efficient in the first run. For that, we need to choose a subset of the initial set of input/output variables which are the most statistical relevant. A combination of Principal Component Analysis (PCA) and a Dimensionality Test (DT) will allow such identification.

The PCA is a multivariate technique that analyze a datatable in which observations are described by several inter-correlated quantitativedependent variables [14]. This method involves the calculation of the eigenvalue 
decomposition of a data covariance matrix or singular value decomposition of a data matrix, usually after mean centering the data for each attribute [22]. For the DT, we use the so-called testdim[23], which allow to test for the number of axes in multivariate analysis. The procedure is based on the computation of the RV coefficient, introduced in [24].We briefly explain it in what follows.

Let $X$ be a table with the measurements of $p$ centered variables (columns) for $n$ units (rows) and set the singular value decomposition of $X^{*}=(1 / \sqrt{n}) X=U D V^{t}$, where $D$ is a diagonal matrix $(r \times r)$ with the $r$ nonnull singular values $D=\operatorname{diag}\left(d_{1}, d_{2}, \ldots, d_{y}\right)$ sorted in decreasing order $\left(d_{1}>d_{2}>\cdots>d_{y}>0\right)$. The column vectors in $U=\left[u_{1}|\ldots| u_{r}\right]$, of size $n \times r$, and $V=\left[v_{1}|\ldots| v_{r}\right]$, of size $p \times r$, are orthonormal and verify $U^{t} U=V^{t} V=I_{y}$. Considering the best approximation of $X$ in the sense of least squares, we have $X=\sum_{j=1}^{\mathrm{i}} X_{j}+R_{\mathrm{i}+1}$, where $X_{j} R X_{i+1}=d_{j} u_{j} v_{j}^{t}$ and $R_{\mathrm{i}}$ represents the residuals[25]. We need to know if an element $\left\{X_{\}_{i}}\right.$ adds relevant information to the decomposition $X_{[i-1]}^{n}$ of rank $i-1$. The test proposed is based on the similarity between $X_{\mathrm{i}} a n d R_{\mathrm{i}}$. The $\mathrm{RV}$ coefficient is a measurement of the closeness between the configuration to the representation of the units in the unidimensional space formed by the $i^{\text {th }}$ principal axis, and the configuration of individuals in the $(r-i+1)$-dimensional space formed by the last $(r-i+1)$ principal axes[15].S.Dray in 2008, see[23], proposed a corresponding dimensional RV statistic defined by $D I M_{R V}\left(X_{\mathrm{i}}, R_{\mathrm{i}}\right)=\frac{\operatorname{tr}\left(X_{\mathrm{i}}^{t} R_{\mathrm{i}} R_{\mathrm{i}}^{t} X_{\mathrm{i}}\right)}{\sqrt{\operatorname{tr}\left(X_{\mathrm{i}}^{t} X_{\mathrm{i}} X_{\mathrm{i}}^{t} X_{\mathrm{i}}\right) \operatorname{tr}\left(R_{\mathrm{i}}^{\mathrm{t}} R_{\mathrm{i}} R_{\mathrm{i}}^{\mathrm{t}} R_{\mathrm{i}}\right)}}=\frac{\lambda_{\mathrm{i}}}{\sqrt{\sum_{j=1}^{v} \lambda_{j}^{2}}}$,

Then our variable selection is made by evaluating the $p$-values for the $i^{\text {th }}$ axis $X_{\mathrm{i}}$, details of the implementation of a randomized algorithm can be found in [23].

\subsubsection{The NC-value}

Comparisons between two groups with different levels of efficiency are made by using, what we call, the NCvalue. This technique was firstly developed by [18], in which the intersection of Gaussian functions are used to measure the disparity between the groups statistics, i.e. it measures the overlapping of its Normal Distributions. Since the notion is quite geometrical see Figure 3, we do not described it here. The smaller the NC-value, the less common the behaviour of the two groups with respect to the selected variables will be, thus is possible to compare the behaviour of input and output variables between groups with different levels of efficiency and determine, from this point view, its statistics along years regarding efficiency, see Section 3.3.1.

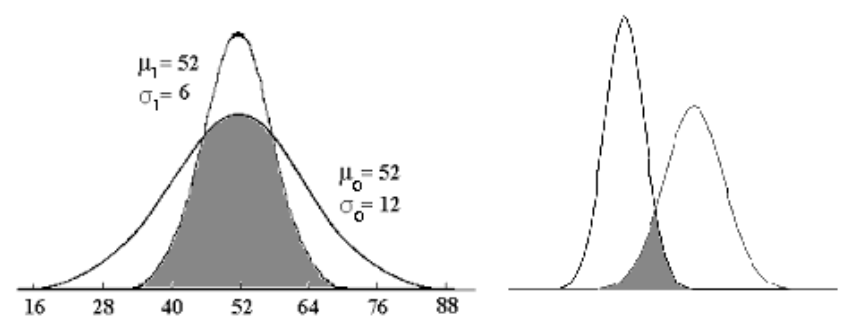

Figure 3:Examples of overlapping of Normal distributions. 


\section{Analysis and Results}

We study the energy efficiency of eight European countries in eight manufacturing sectors for the six years 2008-2013. SeeTable A.2.5@[h4s63ai],for the Gross domestic product at market prices for each country on the studied period. The analysis is presented in three parts: $\left(A_{1}\right)$ general analysis, based on the approach

App01; $\left(A_{2}\right)$ analysis of sectors and inefficiency input usage, based on approach App02; and $\left(A_{2}\right)$ analysis of intensive and non-intensive energy sectors, based on the approach App03. This section may be divided into subsections or may be combined.

\subsection{General analysis $\left(A_{1}\right)$}

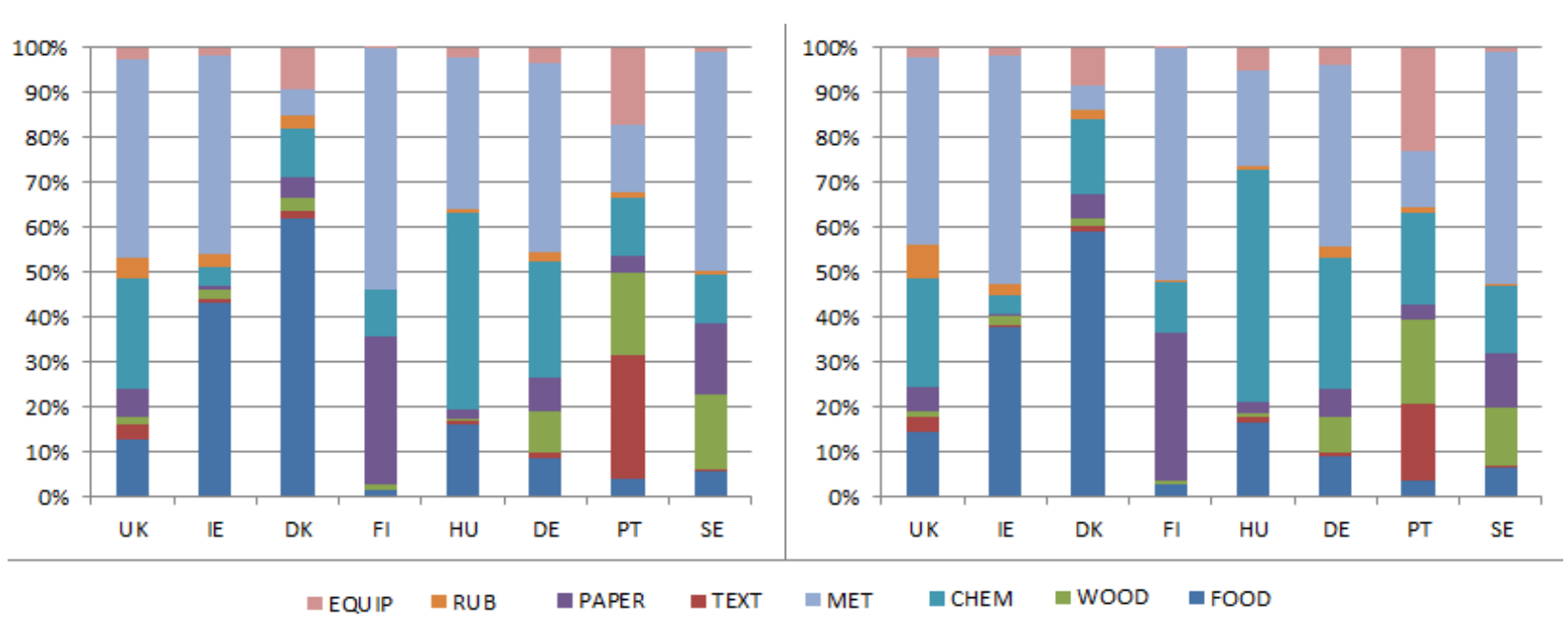

Figure 4:Non-normalized C02 emission comparison between 2008 and 2013.

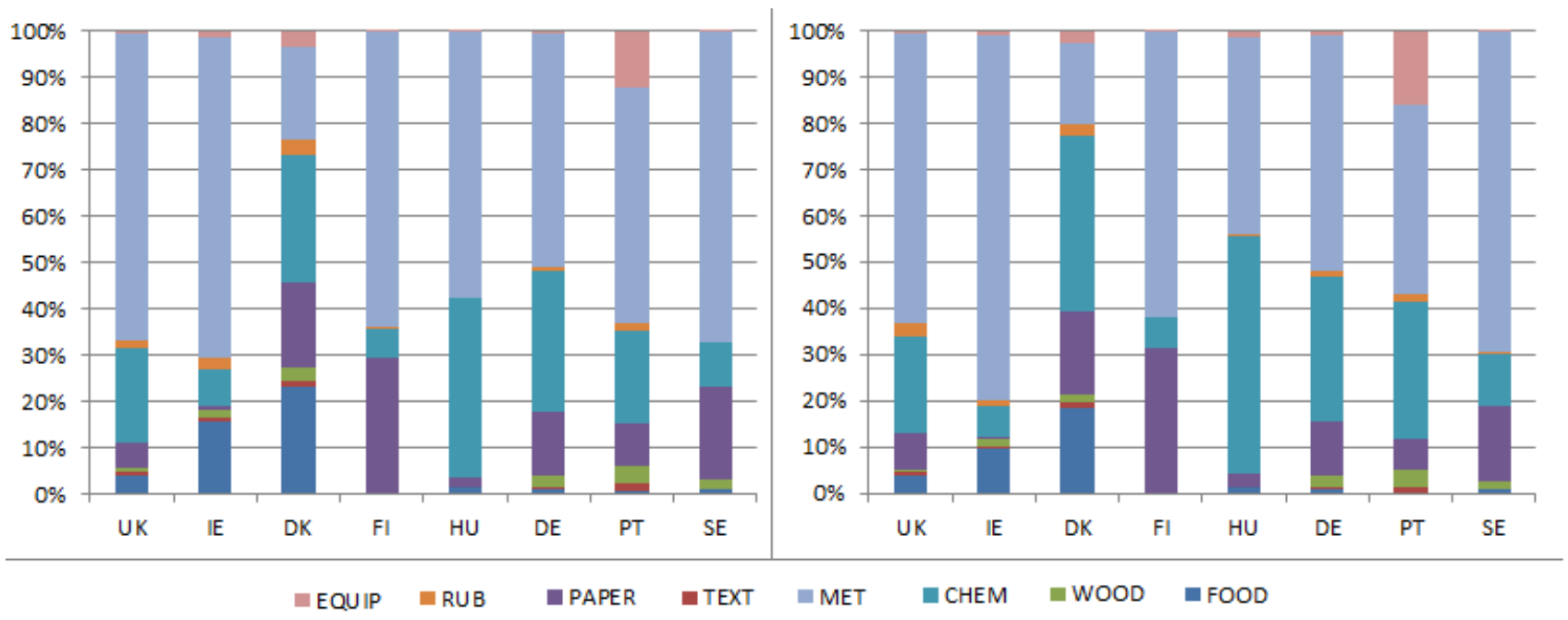

Figure 5: Normalized C02 emission comparison between 2008 and 2013.

In the environment setting, one of the most important measures for energy efficiency of a country is the $\mathrm{CO} 2$ emission. During the sample period the evolution of this variable is notorious. The $\mathrm{C} 02$ emissions in the years 2008 and 2013 by sector for each country are represented in the Figure 4 (non-normalized data) and Figure 5 (normalized data). As we can see the behavior in the two cases is very different. By making a comparison between the normalized and non-normalized $\mathrm{C} 02$ emissions, we can define the impact index on the $\mathrm{CO} 2$ change. In fact, with the potential impact change, shown in Table 2, we can identify which are the priority sectors to create specific policies that maximize the decrease of the total production of $\mathrm{CO} 2$ in a country. This index indicates the degree of influence that each sector has on the emission of $\mathrm{CO} 2$, i.e. the larger the number indicated in Table 2, the greater the impact, indicating that the corresponding sector is more influential in relation to the others. 


\begin{tabular}{|c|c|c|c|c|c|c|c|c|c|c|c|c|c|c|c|}
\hline \multicolumn{2}{|c|}{ UK } & \multicolumn{2}{|c|}{ IE } & \multicolumn{2}{|c|}{ DK } & \multicolumn{2}{|c|}{$\mathrm{FI}$} & \multicolumn{2}{|c|}{$\mathrm{HU}$} & \multicolumn{2}{|c|}{ DE } & \multicolumn{2}{|c|}{ PT } & \multicolumn{2}{|c|}{ SE } \\
\hline FOOD & 3,71 & FOOD & 3,79 & FOOD & 2,55 & WOOD & 11,61 & FOOD & 11,64 & FOOD & 8,49 & TEXT & 13,44 & WOOD & 8,68 \\
\hline EQUIP & 3,58 & EQUIP & 1,78 & EQUIP & 2,49 & TEXT & 11,14 & TEXT & 7,61 & EQUIP & 4,69 & FOOD & 9,57 & TEXT & 7,40 \\
\hline TEXT & 3,51 & RUB & 1,62 & TEXT & 1,04 & FOOD & 9,77 & WOOD & 5,68 & WOOD & 3,31 & WOOD & 4,96 & FOOD & 6,18 \\
\hline WOOD & 3,30 & WOOD & 1,39 & RUB & 0,71 & EQUIP & 8,27 & EQUIP & 4,42 & TEXT & 2,16 & EQUIP & 1,45 & EQUIP & 5,07 \\
\hline RUB & 2,57 & TEXT & 1,11 & CHEM & 0,61 & RUB & 3,25 & RUB & 3,38 & RUB & 2,05 & RUB & 0,95 & RUB & 2,50 \\
\hline CHEM & 1,15 & CHEM & 0,67 & WOOD & 0,60 & CHEM & 1,65 & CHEM & 1,01 & CHEM & 0,94 & CHEM & 0,68 & CHEM & 1,32 \\
\hline PAPER & 0,70 & MET & 0,65 & PAPER & 0,29 & PAPER & 1,06 & PAPER & 0,93 & MET & 0,79 & PAPER & 0,54 & MET & 0,74 \\
\hline MET & 0,67 & PAPER & 0,64 & MET & 0,26 & MET & 0,84 & MET & 0,50 & PAPER & 0,53 & MET & 0,30 & PAPER & 0,74 \\
\hline
\end{tabular}

Table 2: Impact index.

Note that, UK and DE are the countries with the higher CO2 emissions, whereas DK and IE are the countries with lower CO2 emissions. The countries with the highest decrease of CO2 emissions are SE, FI and DK. $\mathrm{CHEM}$ and MET are the sectors with higher $\mathrm{CO} 2$ emissions and the majority of sectors in the countries analyzed show a decrease in the $\mathrm{CO} 2$ emissionsindicating the importance to improve energy efficiency as strategy to decrease $\mathrm{CO} 2$ emissions which concurs with studies of Intergovernmental Panel on Climate Change $[26,27]$.

The efficiency of a unit can be analized from different contexts and approaches. The results depend directly on the model, the variables and the dataset used for the analysis. In the study made by the Japanese Bank Nomura, the metric for efficiency was the amount of energy a country requires to churn out 1 million of gross

domestic product (GDP). In the present study, our methodology and data set, lead to interest results, as we can see in Table B.1.1@[hnu9Inl]-Table B.1.8@[hnu9lnl], which representthe MEA efficiency score for all countries in each sector. The energy efficiency level of some countries like UK, SE and DK, was unexpected in several sectors. In fact, it is well know that the high-tech capitalism drives the Swedish economy exports accounting for engineering with $50 \%$ of the GDP; UK is spurred by the London's financial sector with little energy uses and initiatives like the Low Carbon Transition Plan [28]. However the efficiency levels of these two countries are remarkably low in some sectors. Further, countries that are not as representative in economic terms get surpass them. For example for SE in EQUIP and for UK in CHEM among others.

On the other hand, Germany is one of the world's largest producers of wind turbines and the solar power technology. Therefore, one of the most striking results of this analysis has been the low efficiency of Germany in $50 \%$ of the sectors, namely, FOOD, CHEM, RUB and EQUIP. During the economiccrisis between 2008 and 2010, an increase of intensities of primary and final energy consumption in Germany was observed, i.e. a worsening of energy efficiency. In these years, energy consumption did not completely follow the downward economic development especially in the industrial sector due to a certain part of energy consumption which is independent from the actual production. With the economic recovery in 2011, however, both primary and final energy intensity decreased again at an above-average rate of more than $8 \%$ see[29].

According to our results the most efficient country during the sample period is Ireland with $75 \%$ of the sectors, i.e. TEXT, WOOD, PAPER, CHEM, RUB, MET. This is not surprising since then, the renewable energy use has increased $15 \%$ a year for the last five years.

Other country that stand out for their energy efficiency is Portugal on the sectors FOOD, TEXT, RUB and MET. This may be justified by the fact that portugal has been unachievable in its objective of improving its energy efficiency. Portugal adopted its National Energy Efficiency Action Plan (NEEAP) in 2008. An Energy Efficiency Fund (EEF) was created in 2010 to encourage behavioral changes and raise awareness, and to support energy efficiency projects. In November 2011 the Government raised the primary energy consumption reduction target for 2020 from $20 \%$ to $25 \%$. Portugal, total energy consumption per capita is $34 \%$ below the EU average, at 2.2 toe in 2011. Portugal total energy intensity (i.e. total energy consumption per unit of GDP) measured at purchasing power parity, is $13 \%$ lower than the EU average (2011). Nearly $85 \%$ of the efficiency gains were posted in the industrial sector, while the power sector contributed $16 \%$ to the decrease in overall energy intensity. In 2012, the Fund targeted three fields: industry, residential buildings and public services. A Qualification System of Energy Services Companies (SQESE) was also introduced [30].

With about 5.6 million population Denmark's energy demands are low. This was reflected in the results where only in the sector FOOD, DK presents a marked difference to comparison from the sectors TEXT, WOOD, RUB, EQUIP and MET, in which have a hight efficiency level. 
Countries generally have greater difficulty in improving energy efficiency in the FOOD and CHEM sectors, because of the production processes and technologies used and, in general, these sectors are the highest consumers of energy in the industrial sector [31].

As we can see, in all countries the efficiency score differs from sector to sector. In most cases this difference is also relevant from year to year within the same sector, see Figure 6to know the sectors/countries which have more changes in the ranking.

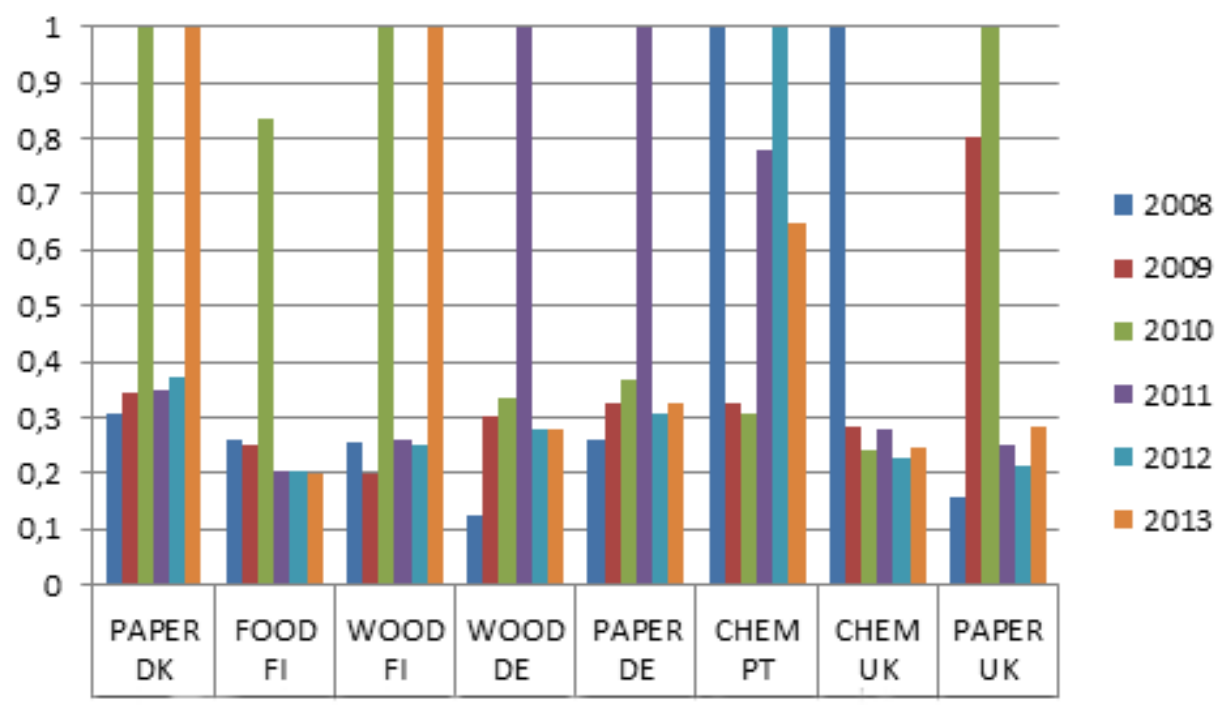

Figure 6: MEA Efficiency.

In the DE case, we see a higher nivel of efficiency in the PAPER sector in the year 2011. In fact, if we make a comparison of 2011 by dividing by the average of the other years (i.e. without considering the year 2011), we observe that there is a decrease in inputs, $\mathrm{E}(0,61 \%), \mathrm{K}(-1,88 \%), \mathrm{LAB}(0,40 \%), \operatorname{INV}(-1,08 \%), \mathrm{ELE}(-0,14 \%)$, FOFUEL(-3,62\%) and EP(-1,02\%), and significant increases in outputs, CO2(-6,14\%), PV $(6,61 \%)$ and VA($0,31 \%)$. It could justify the changes in the Figure 6 for the other countries in a similar way.

\subsection{Analysis of sectors and inefficiency input usage $\left(A_{2}\right)$}

One interesting feature of MEA is that the inefficiency of the input variables can be analyzed individually. In fact, based on the input excess (see Section 2.3.1), we can calculate the following inefficiency index

$\mathrm{R}_{\mathrm{i}}(\mathrm{n})=\frac{\sum_{n=1}^{N} \mathrm{Y}(\mathrm{n})\left(x_{i}(\mathrm{n})-a_{i}^{*}(\mathrm{n})\right)}{\sum_{n=1}^{N} x_{i}(\mathrm{n})}$.

for each given input index $i \in[I]$ and ternary $n \in N$ by using the ideas in [34], in order to know the number of

times each input was used inefficiently, since our particular interest is to assess to what extent the efficiency can be improved with less inputs.

Before starting, it is important to note that in this subsection, we will focus mainly on the inefficiency index (see Equation (5)), since much of the analysis by sector was under consideration in the previous approach. Table A.2.2@[h4s63qishowsthe number of enterprises by sector along years, indicating that the number of industries is stable, except for FOOD in 2009 where the number of enterprises dropped sharply as a result of the economic crisis experienced in Europe in that period. 


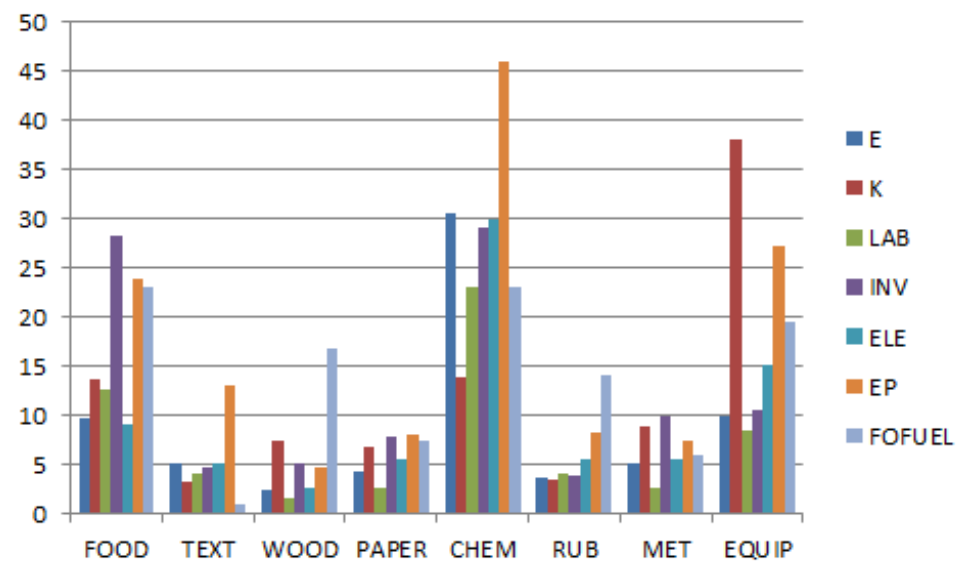

Figure 7: Inefficiency index.

To analyze in more detail the contribution of each variable in the model, we computed the index of inefficiency in all sectors (see Equation(5)). The percentages in Table. The percentages in Table C.1.1@[jt5b4s7]and Figure 7 represent the number of times each input was used ine_ciently (excess inputs), throughout the sstudy years. During the sample period, the sector that uses more inefficiently the variables is CHEM followed by EQUIP and FOOD. Meanwhile, TEXT and WOOD stand out for the low percentage of inefficiency in the use of the variables. It is noteworthy that of all the variables analyzed, EP is the variable used more inefficiently with an average of $17,29 \%$, having its peak in the CHEM sector $(46,03 \%)$. On the other hand, the variable less used inefficiently is $L A B$ with an average of $7,38 \%$.

\subsection{Analysis of intensive and non-intensive sectors $\left(A_{3}\right)$}

Sectors are generally grouped in intensive energy sectors and non-intensive energy sectors. This cluster division, however, is usually made according to some energy tax law criteria in each specific country. Such separation are key points for energy analysis and are considered in energy studies in the literature. For example, in[3], the energy sectors were identified by taking into account German energy tax law and by using cluster analysis. Since the present study involves eight countries, here the selection of the clusters is made by using an algorithm for performing non-hierarchical clustering, the Partitioning Around Medoids (PAM) proposed by [16].The PAM is based on the GDM2 distance measure proposed in [17].The selected variables by PAM are K, E and PV and the algorithm results determine that the best data grouping corresponds to the clusters: intensive energy sector ( $\mathrm{cl} 1$ )and non-intensive energy sector (cl2),represented in Table 3 for each country, first for non-normalized data and then for normalized data. The results for the two cases are very stable. in fact, in the non-normalized data case, only one cluster change is presented once in PT in the PAPER sector and in the normalized data case twice in DK in the MET sector. Note that the final cluster is the the most frequent cluster along the years (calculated using the rounded average). As we can see the classification of sectors is very different when the data are normalized. In fact, only the FOOD sector remains in the same classification in both cases (normalized and non-standardized data) for all countries. 
Table 3: Intensive vs Non-Intensive

Classification.

\begin{tabular}{|c|c|c|c|c|c|c|c|c|c|}
\hline \multicolumn{10}{|c|}{ NON-NORMALIZED DATA } \\
\hline & DK & FI & DE & HU & IE & PT & SE & UK & Final Cluster \\
\hline TEXT & $\mathrm{Cl} 2$ & $\mathrm{Cl} 2$ & $\mathrm{Cl} 2$ & $\mathrm{Cl} 2$ & $\mathrm{Cl} 2$ & $\mathrm{Cl} 2$ & $\mathrm{Cl} 2$ & $\mathrm{Cl} 2$ & $\mathrm{Cl} 2$ \\
\hline PAPER & $\mathrm{Cl} 2$ & $\mathrm{Cl} 1$ & $\mathrm{Cl} 2$ & $\mathrm{Cl} 2$ & $\mathrm{Cl} 2$ & $\mathrm{Cl} 2$ & $\mathrm{Cl} 1$ & $\mathrm{Cl} 2$ & $\mathrm{Cl} 2$ \\
\hline CHEM & $\mathrm{Cl} 1$ & $\mathrm{Cl} 1$ & $\mathrm{Cl} 1$ & $\mathrm{Cl} 1$ & $\mathrm{Cl} 1$ & $\mathrm{Cl} 2$ & $\mathrm{Cl} 1$ & $\mathrm{Cl} 1$ & $\mathrm{Cl} 1$ \\
\hline RUB & $\mathrm{Cl} 2$ & $\mathrm{Cl} 2$ & $\mathrm{Cl} 2$ & $\mathrm{Cl} 1$ & $\mathrm{Cl} 2$ & $\mathrm{Cl} 1$ & $\mathrm{Cl} 2$ & $\mathrm{Cl} 2$ & $\mathrm{Cl} 2$ \\
\hline
\end{tabular}

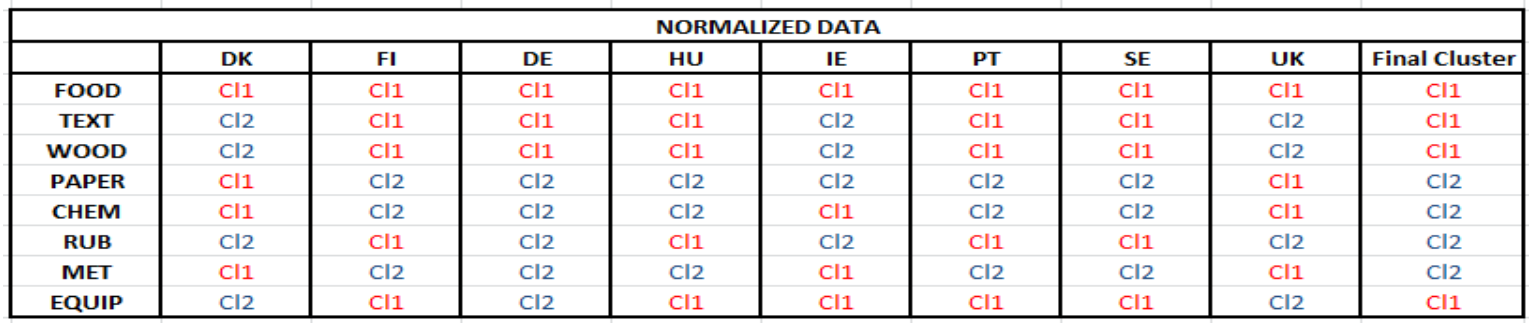

According to the results, in non-normalized data case the intensive energy sectors are FOOD, CHEM, MET and EQUIP; and the non-intensive energy sectors are TEXT, WOOD, PAPER and RUB. When the data are normalized the intensive energy sectors are FOOD, TEXT, WOOD and EQUIP; and the non-intensive energy sectors are PAPER, CHEM, RUB and MET. The cluster analysis also shows that in the non-normalized data the Danish, Irish, Portuguese and British manufacturing industry has fewer intensive energy sectors than the others countries. In normalized data, are the Irish and German manufacturing industry that presented more non-intensive energy sectors (i.e. three sectors each one).

In the rest of the paper, the (final) clusters used are the ones corresponding to the normalized data. Define $C L_{y}$ as the set of sector/country/year ternaries $\mathrm{n}=(\mathrm{s}, \mathrm{c}, \mathrm{t})$ such that $\mathrm{s}$ belongs to the cluster $r e\{1,2\}$.

A summary of the resulting efficiency ratios for the second application is provided in the Table 4, classified in intensive energy sectors and non-intensive energy sectors. For that, define $E F F_{F}^{t}$ as subset of sector/country/year ternaries $n \in C L_{y}$ such $0.6 \leq \operatorname{MEA}\left(s_{,}, c_{s} t\right) \leq 1.0$ for a fixed year $t \in[T]$. Recall that $\operatorname{MEA}(s, \mathrm{c}, \mathrm{t})$ denotes the MEA efficiency score, see (Equation (1)). Fixed a year $t \in[T]$ and a cluster $r E\{1,2\}$, we may extract four relevant quantities: (a) the total mean efficiency; (b) $E F F_{F}^{t}$ mean (c) $E F F_{F}^{t}$ Total (i.e. the percentage of EFF efficient sectors); and (d) Full Efficiency (i.e. the percentage of sectors with MEA efficiency score equal to 1 .

Table 4: Ratios of efficiency.

\begin{tabular}{|c|c|c|c|c|}
\hline \multicolumn{5}{|c|}{ Ratios of Efficiency, Intensive Energy Sector } \\
\hline Year & $\begin{array}{c}\text { Total } \\
\text { mean }\end{array}$ & $\begin{array}{c}\text { EFF } \\
\text { mean }\end{array}$ & $\begin{array}{c}\text { EFF/Total } \\
\text { (\%) }\end{array}$ & $\begin{array}{c}\text { Full Eff. } \\
\text { (\%) }\end{array}$ \\
\hline $\mathbf{2 0 0 8}$ & 0,606 & 0,948 & 51,4 & 40 \\
$\mathbf{2 0 0 9}$ & 0,573 & 0,967 & 45,7 & 40 \\
$\mathbf{2 0 1 0}$ & 0,546 & 0,954 & 40 & 31,4 \\
$\mathbf{2 0 1 1}$ & 0,546 & 0,979 & 40 & 37,1 \\
$\mathbf{2 0 1 2}$ & 0,546 & 0,982 & 40 & 37,1 \\
$\mathbf{2 0 1 3}$ & 0,49 & 0,952 & 34,3 & 28,6 \\
\hline
\end{tabular}

\begin{tabular}{|c|c|c|c|c|}
\hline \multicolumn{5}{|c|}{ Ratios of Efficiency, Non-Intensive Energy Sector } \\
\hline Year & $\begin{array}{c}\text { Total } \\
\text { mean }\end{array}$ & $\begin{array}{c}\text { EFF } \\
\text { mean }\end{array}$ & $\begin{array}{c}\text { EFF/Total } \\
\text { (\%) }\end{array}$ & $\begin{array}{c}\text { Full Eff. } \\
\text { (\%) }\end{array}$ \\
\hline $\mathbf{2 0 0 8}$ & 0,685 & 0,943 & 59,6 & 44,8 \\
$\mathbf{2 0 0 9}$ & 0,601 & 0,924 & 51,7 & 37,9 \\
$\mathbf{2 0 1 0}$ & 0,788 & 0,93 & 75,9 & 51,7 \\
$\mathbf{2 0 1 1}$ & 0,796 & 0,934 & 75,9 & 55,2 \\
$\mathbf{2 0 1 2}$ & 0,789 & 0,931 & 79,3 & 55,2 \\
$\mathbf{2 0 1 3}$ & 0,744 & 0,932 & 72,4 & 51,7 \\
\hline
\end{tabular}

Clearly, there is a big difference between the ratios of the two clusters. The intensive energy sectors have achieved greater efficiency during the study period, except in 2009, in which the non-intensive energy sector 
surpasses 6\%. The Figure D.1.3@[znodlbp]and Figure D.1.4@[znodlbp]show the full and the mean efficiency

for the two groups during the studied period. The non-intensive energy sectors have a higher number of sectors with efficiency equal to 1 than the intensive energy sector, except in 2009. The opposite is the situation when it comes to analyze the mean EFF, in which the energy intensive sectors are always higher than the non-intensive energy sectors.

\subsubsection{Efficient versus non-efficient groups}

Table 5: NC-values for intensive and non-intensive sectors.

\begin{tabular}{|c|c|c|c|c|c|c|c|c|c|c|}
\hline & $\mathrm{CO2}$ & E & ELE & EP & FOFUEL & INV & K & LAB & PV & VA \\
\hline Intensive & $3,637 \mathrm{E}-06$ & $1,721 \mathrm{E}+01$ & $5,895 \mathrm{E}+01$ & $8,696 \mathrm{E}-02$ & $2,077 E+01$ & $2,309 E-02$ & $2,692 \mathrm{E}-02$ & $8,394 \mathrm{E}-05$ & $6,300 \mathrm{E}-04$ & $8,057 \mathrm{E}-03$ \\
\hline Non-intensive & $4,761 \mathrm{E}-06$ & $2,241 \mathrm{E}+01$ & $9,367 E+01$ & $4,859 \mathrm{E}-01$ & $2,220 E+01$ & $8,149 \mathrm{E}-02$ & $1,992 \mathrm{E}-02$ & $4,590 \mathrm{E}-04$ & $2,823 \mathrm{E}-03$ & $8,660 \mathrm{E}-03$ \\
\hline Intensive & 1 & 15 & 19 & 13 & 16 & 10 & 11 & 3 & 5 & 7 \\
\hline Non-intensive & 2 & 18 & 20 & 14 & 17 & 12 & 9 & 4 & 6 & 8 \\
\hline
\end{tabular}

For a detailed analysis, from now on, we will consider two groups for each sector according to the MEA efficiency score: the group $G_{1}$ corresponding to the most efficient sectors $0.6 \leq M E A(n) \leq 1.0$ and the group

$G_{0}$ corresponding to the less efficient sectors $\left(0.0 \leq \operatorname{MEA}\left(s, c_{s} t\right) \leq 0.4\right)$. We calculate the NC-value in each

variable and the result for intensive and non-intensive energy sectors are represented in Table 5 and FigureD.2.1@[znodlbp]-FigureD.2.10@[znodlbp]. Here, the more efficient group is represented by a blue line and the less efficient group is represented by a black line, see Figure 8for the variable CO2.
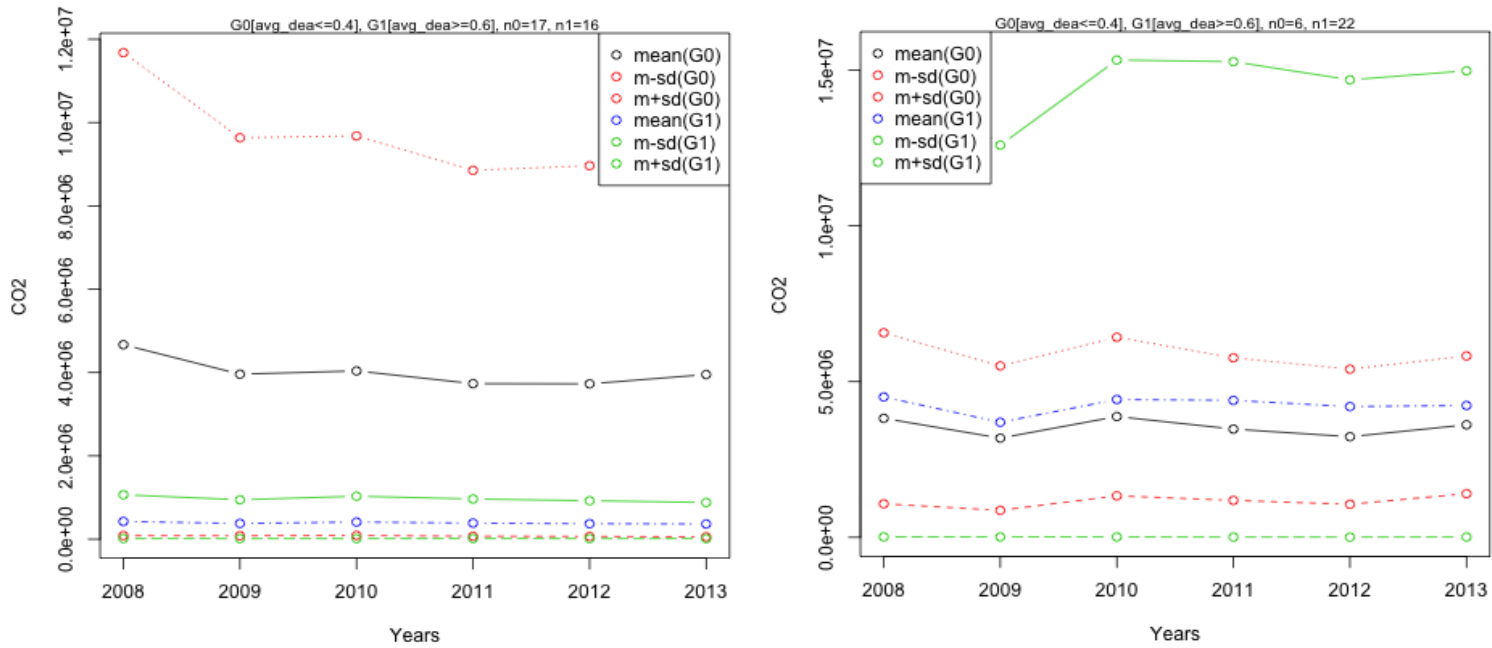

(a) Intensive sector (b)Non-intensive sector

Figure 8: Two groups statistics for $\mathrm{CO} 2$ emission.

The smaller the NC-value, the less common the behaviour of the two groups with respect to the selected variables will be (see Section 2.3.5). The figures $8(a)$ and $8(b)$, shown notorious differences in the behaviour of the variables and the groups. For example, in intensive energy sectors, the C02 emission, E, FOFUEL and ELE consumption, in the $G_{1}$ group have less consumption than the $G_{0}$ group. These findings are important to analyze differences of energy efficiency performance among industrial sectors and countries demonstrated the importance to strength measures of energy efficiency in chemical and food industries and especially in non-intensive energy sectors that day to day increase number of enterprises and energy use.

\section{Conclusions and Final Discussion}

The manufacturing industrial sectors are a large energy consuming area of the European economy, accounting for almost one-third of energy consumption. In this work several techniques, including the Multidirectional Efficiency Analysis (MEA), are used to compute energy-efficiency performance, from 2008 to 2013, for eight European countries in eight manufacturing sectors. The study is undertaken under several approaches, described in Figure 1 and Figure 2 in order to extract the most relevant information. 
In our results, we observed that inputs like investments and energy prices are determinants on energy efficiency in the manufacturing industries, between 2008 and 2013. Precisely in this period, there were significantly economic changes due to the world financial crisis, which affected substantially some sectors like FOOD and CHEM. The countries under study with the best level of efficiency, for the variables considered, were suprisenly Ireland, Portugal and Denmark. As expected, performance in efficiency is very different in the intensive and non-intensive sectors. Among the most efficient sectors are the non-intensive sector RUB and the intensive sector WOOD and among the least efficient sectors are the intensive sector FOOD and the nonintensive sector CHEM. Further analysis was already given in Section 3.

In order to have a global idea of the energy performance of each country, we now rank them according to their efficiency by defining a score that is a MEA weighted aggregation of all sectors in each country and year. For this, let $E(s, c, t)$ be the number of enterprises for a given ternary $n=(s, c, t) \in N$. We calculate the

(country/year) MEA weighted score as

$\left.W-M E A_{Z}(c, t)=\sum_{s \in S}\left(\frac{E(s, c, t)}{\sum_{\delta E S} E\left(s_{s}, t\right)}\right) M E A_{Z}(s, c, t)\right)$.

where $e C$ is a country, $t \in T$ is a year, and $M E A(n)$ is the MEA score (see Equation (1)). The results are

represented in Table 6 and Figure 9. Recall that the data is normalized, but for each country/year, the MEA index is invariant to such normalization. As we can see in the figure, in the first two years of study, Hungary and Ireland manage to stay on top of all countries with a noticeable difference. Although Ireland continues to maintain a higher level of efficiency, Hungary presents a very significant decline that only improves in 2012. With almost a flat performance, Denmark does not present a great variance compared with other countries, so it looks like Denmark was not greatly affected by the crisis. United Kingdom shows a kind of paraboloid behavior, always remaining above the average, except in the extreme years. Finland performance is among the most unstable. Portugal is a great surprise in this study, since it managed to have a significantly upward performance that led him to position in the first places in the last three years. We may conjecture that the crisis had a positive compensation effect in these countries, however U.K. had a kind of inertial phenomena which make it return to the reference values before the crisis. Such is different for Portugal, maybe because of the economic restrictions imposed by Troika which created an indirect positive performance improvement for a longer period. We may also notice the known fact that Portugal has some delay response compared with other European countries. On the other hand, Germany and Sweden in this weighted score placed in the last places of the ranking, although particularly Germany maintained a tendency to improve its performance, except in the year 2012 and Sweden from the second period of study maintained an ascending performance, showing great advances in the last four years. These fact is of great surprise and the data used in this study seems not enough to formulate a reasonable explanation. A detailed study is needed to understand such phenomena for Germany.

Table 6: Weighed MEA ranking by country.

\begin{tabular}{|c|c|c|c|c|c|c|c|c|}
\hline Year & Denmark & Finland & Germany & Hungary & Ireland & Portugal & Sweden & United K. \\
\hline 2008 & 0,579 & 0,420 & 0,244 & 0,888 & 0,848 & 0,327 & 0,274 & 0,452 \\
\hline 2009 & 0,701 & 0,397 & 0,317 & 0,859 & 0,924 & 0,497 & 0,272 & 0,711 \\
\hline 2010 & 0,746 & 0,908 & 0,339 & 0,497 & 1,000 & 0,862 & 0,279 & 0,882 \\
\hline 2011 & 0,706 & 0,581 & 0,451 & 0,497 & 0,687 & 0,995 & 0,564 & 0,809 \\
\hline 2012 & 0,633 & 0,574 & 0,283 & 0,984 & 1,000 & 0,997 & 0,708 & 0,592 \\
\hline 2013 & 0,715 & 0,756 & 0,316 & 0,267 & 0,935 & 0,966 & 0,741 & 0,266 \\
\hline
\end{tabular}




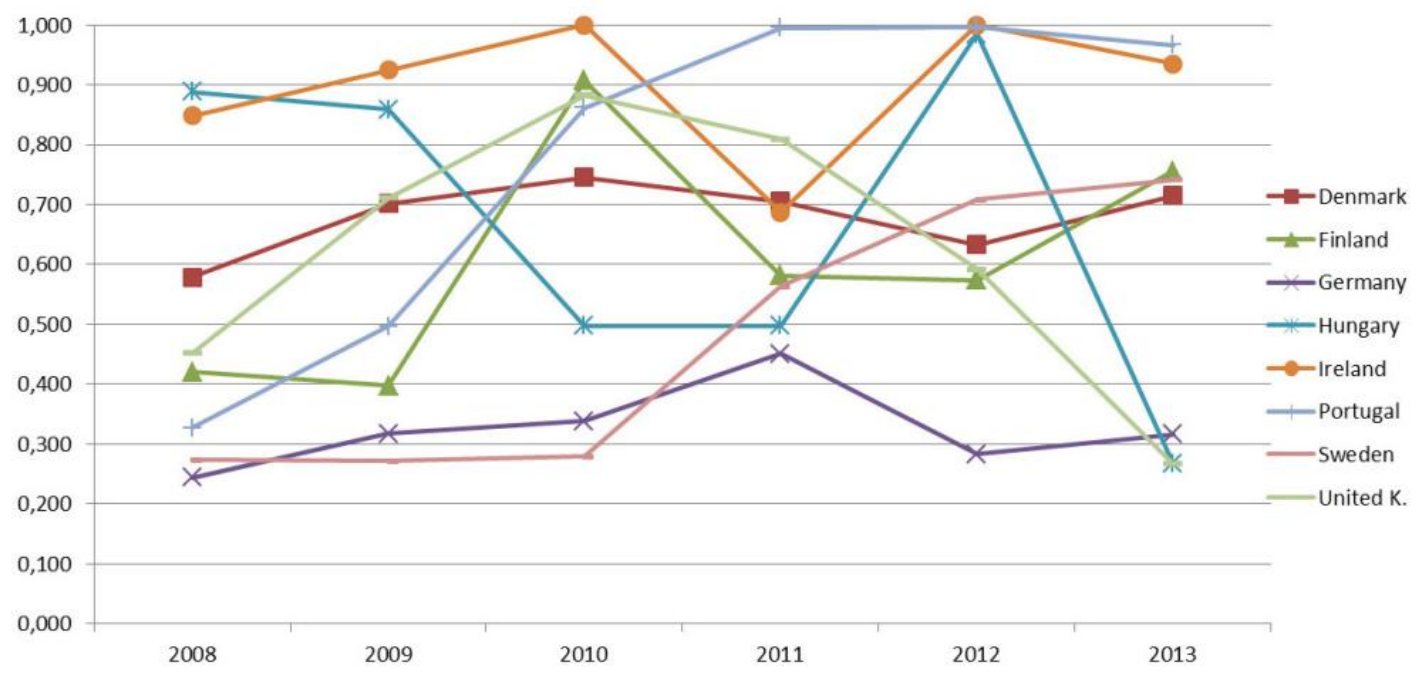

Figure 9:Weighed MEA ranking by country.

A global observation is the fact that the majority of the countries improved their energy efficiency and decreased $\mathrm{CO} 2$ emissions during the sample period, demonstrating that energy and indirect variables (e.g. the country economy situation) are key issues within the manufacturing structure and productivity.

Since the period of study includes the European financial crisis, we may conjecture that there was (at least) two general trends in the manufacturing firms sectors: (a) the total production was reduced because there was less demand, so less energy consumption was needed; and (b) they reduced expenses and improved the manufacturing efficiency.

These statements may justify why the weighted MEA efficiency score increased along the years, being the maximum average value attained in 2012. Further and detailed studied are needed to check these hypotheses, with a completely new set of source data.

The methods used seem to be adequate to undertake a detailed analysis, compared energy efficiency performance and trends in $\mathrm{CO} 2$ emissions, which are important as input to policy makers. Moreover, inefficiency index exposes the in excess inputs used which are relevant for optimization strategies in the production structure and resource management. In fact, the shown results have significant policy suggestions to improve energy efficiency and decrease $\mathrm{CO} 2$ emissions. We hope that the study demonstrate the importance of energy efficiency management, especially in non-intensive energy sectors, help players and decision makers to develop adequate instruments for the application of energy efficient best practices and innovations, and new ways for energy conservation in the manufacturing sectors, which may have a significant impact on economics and the environment.

\section{Data Availability (excluding Review articles)}

The reader interested in accessing the output data, in the form of tables and graphs, may check the web address http://sdl-vm2.mathdir.org/docs/pris/000012-public.html. Input data is not provided since it belongs to the Eurostata and Odyssee databases.

\section{Conflicts of Interest}

Theauthors of this work do not have any conflict of interests.

\section{Funding Statement}

Work partially supported by Portuguese funds through the Center for Research and Development in Mathematics and Applications (CIDMA) and the Portuguese Foundation for Science and Technology (FCT), within project UID/MAT/04106/2013; funded by Project 3599-Promover a ProduçãoCientífica e DesenvolvimentoTecnológico e a Constituição de RedesTemáticas (3599-PPCDT) and FEDER funds through COMPETE 2020, ProgramaOperacionalCompetitividade e Internacionalização (POCI), and by national funds through FCT; Murillo is also supported by the FCT post-doc fellowship SFRH/BPD/97085/2013.

\section{References}

[1] A. Charnes, W. Cooper, E. Rhodes, Measuring the efficiency of decision making units, European Journal of Operational Research,2 (1978), 429-444. 
[2] K. Mukherjee, Energy use efficiency in U.S. manufacturing: A nonparametric analysis, Energy Economics, 30 (2008), 76-96.

[3] C. P. Martínez, Energy eficiency development in german and colombiannon-energy-intensive sectors: A non-parametric analysis, Journal EnergyEficiency, 4 (1), (2011), 115-131.

[4] M. Alsahlawi, Measuring energy efficiency in GCC countries, The Journalof Business Inquiry, (2013), 15-30.

[5] F. Camioto, D. Rebelatto, R. Rocha, Energy efficiency analysis of BRICS countries: a study using data envelopment analysis, The Journal of Business Inquiry, (2016), 192-203.

[6] R. Pahlavan, M. Omid, S. Ra_ee, S. H. Mousavi-Avval, Optimization ofenergy consumption for rose production in iran, Energy for SustainableDevelopment, 16 (2012), 236-241.

[7] P. Bogetoft, J. Hougaard, Efficiency evaluations based on potential (nonproportional) improvements, Journal of Productivity Analysis, 12 (3) (1999),233-247.

[8] K. Wang, S. Yu, M. Li, Y. M. Wei, Multi-directional efficiency analysisbased regional industrial environmental performance evaluation of china,Natural Hazards, 75 (2014), 273-299. doi:http://dx.doi.org/10.1007/s11069-014-1097-4.

[9] G. Bi, P. Wang, F. Yang, L. Liang, Energy and environmental efficiency ofchinas transportation sector: A multidirectional analysis approach, Mathematical Problems in Engineering, (2014), 1-13. doi:http://dx.doi.org/10.1155/2014/539596.

[10] K. Wang, Y. M. Wei, X. Zhang, Energy and emissions efficiency patternsof chinese regions: A multidirectional efficiency analysis, Applied Energy, $104 \quad$ (2013), 105-116. doi:http://dx.doi.org/10.1016/j.apenergy.2012.11.039.

[11] B. Wang, I. Nistor, T. Murty, Y.-M. Wei, Efficiency assessment of hydroelectric power plants in canada: A multi criteria decision making approach,Energy Economics, 46 (2014), 112-121.

[12] M.Asmild, T. Holvad, J. L. Hougaard, D. Kronborg, Railway reforms: Dothey inuence operating efficiency?, Transportation,5 (36), (2009), 617-638.

[13] T. Holvad, J. L. Hougaard, D. Kronborg, H. K. Kvist, Measuring ineficiency in the norwegian bus industry using multi-directional efficiencyanalysis, Transportation, 31 (3) (2004), 349-369.

[14] K. Pearson, On lines and planes of closest $t$ to systems of points in space,Philosophical Magazine Series,6 (2) (1901) ,559-572.

[15] P. Robert, Y. Escou_er, A unifying tool for linear multivariate statisticalmethods: the $r v$ coeficient, Appl. Statist., (25) (1976), 257-265.

[16] L. Kaufman, P. Rousseeuw, Finding groups in data: an introduction tocluster analysis, New York: Wiley.

[17] M. Walesiak, Statystyczna analiza wielowymiarowa $w$ badaniach marketingowych [multivariate statistical analysis in marketing research], Wroclaw University of Economics, Research Papers (654).

[18] H. Inman, E. Bradley Jr, The overlapping coe_cient as a measure of agreement between probability distributions and point estimation of the overlapof two normal densities, communications in statistics, Theory and Methods, 18 (10) (1989), 3851-3874.

[19] R. Banker, A. Charnes, W. Cooper, Some models for estimating technicaland scale ine ciencies in data envelopment analysis, Management Science,30 (9) (1984), 1078-1092.

[20] M. Walesiak, A. Dudek, Searching for optimal clustering procedure for adata set, Package ClusterSim version: 0.45-1, (2016), 1-69.

[21] K. Karun, E. Isaac, Cogitative analysis on k-means clustering algorithmand its variants, Int J Adv Res Comp Communi Eng., 4 (2) (2013), 1875-1880.

[22] X. Chen, C. Chen, L. Jin, Principal component analysis in anthropologicalgenetics, Advances in Anthropology, (1) (2011), 9-14. doi:http://dx.doi.org/10.4236/aa.2011.12002.

[23] S. Dray, On the number of principal components: A test of dimensionality based on measurements of similarity between matrices, ComputationalStatistics and Data Analysis, 52 (2008), 2228-2237.

[24] P. Robert, Y. Escoufier, A unifying tool for linear multivariate statisticalmethods: the rv coe_cient, Appl. Statist. 25 (1976) 257-265. 
[25] I. Good, Some applications of the singular decomposition of a matrix, Technometrics, (11) (1969) 823831.

[26] Fourth assessment report of the intergovernmental panel on climate change, https://www.ipcc.ch/publications_and_data/ar4/syr/en/contents.html (2007).

[27] V. Kuuskraa, P. DiPietro, K. Scott, S. Forbes, Future U.S. greenhousegas emission reduction scenarios consistent with atmospheric stabilization,JAF024095.DOC. GHGT-7 Paper ID 506.

[28] The UK low carbon transition plan, http://www.isi.fraunhofer.de/isi-wAssets/docs/x/de/publikationen/

National-Report_Germany_November-2012.pdf (2009).

[29] Energy efficiency policies and measures in germany, http://www.isi.fraunhofer.de/isi wAssets/docs/x/de/publikationen/National Report_Germany_November-2012.pdf (2010).

[30] Portugal, energy efficiency report, https://library.e.abb.com/public/791d25e3fa3537b6c1257be800558fa8/Portugal.pdf (2013).

[31] G. Schaumann, The efficiency of the rational use of energy, Applied Energy,84 (2007), 719-728.

[32] P. Bogetoft, J. Hougaard, Super efficiency evaluations based on potentialslack, European Journal of Operational Research, 152 (1) (2004), 14-21.

[33] M. Asmild, J. Pastor, Slack free MEA and RDM with comprehensive efficiency measures, Omega, 38 (6) (2010), 475-483.

[34] P. Bogetoft, L. Otto, Benchmarking with dea, sfa, and r, InternationalSeries in Operations Research and Management Science, 157 (2011), 1-351. 